\title{
POTENCIAL FISIOLÓGICO DE DOIS LOTES DE SEMENTES DE ARROZ TRATADAS COM 24-EPIBRASSINOLÍDEO ${ }^{1}$
}

\author{
CRISTINA FERREIRA LARRÉ2; DARIO MUNT DE MORAES³ NEI FERNANDES LOPES ${ }^{3}$
}

\begin{abstract}
RESUMO - Os reguladores de crescimento vegetal estão envolvidos na promoção e inibição do processo germinativo, entre estes os brassinosteróides. O objetivo da pesquisa foi avaliar o desempenho de diferentes concentrações de 24-epibrassinolídeo na qualidade fisiológica de sementes e no crescimento de plântulas de arroz (Oryza sativa L.) em dois lotes da cv. IRGA 422CL. O experimento foi realizado no Laboratório de Sementes e na casa de vegetação do Departamento de Botânica da Universidade Federal de Pelotas (UFPel). As sementes de ambos os lotes foram tratadas com concentrações crescentes de 24-epibrassinolídeo (zero; 0,01; 0,1;0,4 e 1,0 $\mu \mathrm{M}$ ), por um período de duas horas e avaliadas por meio dos testes de germinação, primeira contagem da germinação, índice de velocidade de germinação, emergência, índice de velocidade de emergência, condutividade elétrica, comprimento de parte aérea e de raiz e massas fresca e seca de parte aérea e raiz. O delineamento experimental utilizado foi o inteiramente casualizado, com três repetições. As médias foram comparadas pelo teste de Tukey a $5 \%$ de probabilidade e submetidas à análise de regressão polinomial. Concentrações mais baixas $(0,01$ e $0,1 \mu \mathrm{M})$ de 24-epibrassinolídeo incrementam o potencial fisiológico das sementes da cv. IRGA 422CL pois, proporcionam maiores taxas de crescimento no período inicial do estabelecimento da cultura. $\mathrm{O}$ incremento na concentração do fitohormônio acentua o processo de deterioração das sementes reduzindo a viabilidade e o vigor das sementes da cultivar estudada. De modo geral em todas as características determinadas, concentrações menores ou iguais a $0,4 \mu \mathrm{M}$ de 24 -epibrassinolídeo produziram respostas positivas na qualidade fisiológica das sementes de arroz cv. IRGA 422CL.
\end{abstract}

Termos para indexação: brassinosteróides, germinação, Oryza sativa L.

\section{POTENTIAL PHYSIOLOGICAL OF RICE SEEDS TREATED WITH 24-EPIBRASSINOLIDE}

\begin{abstract}
Plant growth regulators are involved in promoting and inhibiting germination process, and include the brassinosteroids. The objective of the research was evaluate the performance of different concentrations of 24-epibrassinolide on the seed physiological quality and seedling growth in two lots of rice cv. IRGA 422CL. The experiment was carried out in the Seed Laboratory and at in the greenhouse in the Botany Departament, Pelotas Federal University (UFPel). The seeds of both lots were treated with increasing concentrations of 24-epibrassinolide, zero, 0.01, 0.1, 0.4 and $1.0 \mu \mathrm{M}$, for a period of two hours and evaluated by the tests of germination, the first germination count, the germination speed index, emergence, emergence speed index, electrical conductivity, shoot and root length and shoot and root fresh and dry matter. A randomized complete design with three replications was used with three replications. Means were compared by the Tukey test
\end{abstract}

${ }^{1}$ Submetido em 01/10/2008. Aceito para publicação em 16/06/2009. Parte da Dissertação de Mestrado do primeiro autor apresentada à UFPel.

${ }^{2}$ Bióloga, pós-graduanda do Departamento de Botânica, UFPel/IB, cristina larre@yahoo.com.br.
${ }^{3}$ Eng. Agr. Dr., Professor Titular, Departamento de Botânica, UFPel, Caixa postal 354 CEP: 96010-900 . Pelotas, moraesdm@ufpel.tche.br. neilopes@ufpel.edu.br. 
at 5\% probability and subjected to polynomial regression analysis. Lower $(0.01$ and $0.1 \mu \mathrm{M}) 24$ epibrassinolídeo concentrations increased the seed physiological potential of cv. IRGA 422CL and therefore provided higher growth rates in the initial period of crop establishment. The increase in the plant hormone concentration accelerated the seed deterioration process reducing the viability and vigor of cultivar seedsstudied. Generally in all the determined characteristics, concentrations less than or equal to $0.4 \mu \mathrm{M} 24$-epibrassinolide produced a positive response in the seed physiological quality rice cv. IRGA 422CL.

Index terms: brassinosteroids, germination, Oryza sativa L.

\section{INTRODUÇÃO}

Os brassinosteróides são atualmente considerados como um novo grupo de fitohormônios com significantes propriedades promotoras do crescimento. A partir do isolamento do primeiro brassinolídeo, na década de 1960, mais de 60 tipos de brassinosteróides já foram identificados em diversos órgãos em plantas de diferentes espécies. Entre os de ocorrência natural, o brassinolídeo e a castasterona são considerados os mais importantes devido a sua ampla distribuição e atividade metabólica (Zullo e Adam, 2002).

Testes com 24-epibrassinolídeo e 28-epibrassinolídeo, análogos do brassinolídeo, comprovaram que os brassinosteróides não só promovem a germinação de sementes como podem reverter o efeito inibitório do ácido abscísico sobre a germinação (Rao et al., 2002).

$\mathrm{O}$ uso de sementes com potencial fisiológico elevado é fundamental para a obtenção de resultados satisfatórios em culturas de expressão econômica. Neste sentido, pesquisas que permitam diagnosticar a qualidade das sementes produzidas poderão possibilitar o emprego de técnicas mais eficientes, com resultados promissores para os cultivos.

O potencial fisiológico das sementes é rotineiramente avaliado pelo teste de germinação, conduzido sob condições altamente favoráveis de temperatura, umidade e substrato, viabilizando assim, o máximo potencial para germinação. Os resultados desse teste apresentam confiabilidade para analistas e produtores de sementes, sob o aspecto de reprodutibilidade dos dados, tendo como finalidade obter informações acerca da qualidade de diferentes lotes com vistas à comercialização (Zepka et al., 2007). No entanto, Byrum e Copeland (1995) questionam a validade deste teste para predizer o comportamento das sementes em campo, onde as condições nem sempre são favoráveis e sugerem a complementação do teste de germinação com o teste de emergência de plântulas no campo a fim de identificar lotes com melhor desempenho.

A qualidade fisiológica da semente pode ser avaliada por duas características fundamentais, a viabilidade e o vigor (Popinigis, 1977). A viabilidade é determinada pelo teste de germinação, um fenômeno biológico que pode ser considerado pelos botânicos como a retomada do crescimento ativo por parte do embrião, com o subseqüente rompimento do tegumento pela radícula. Entretanto, para os tecnologistas de sementes, a germinação é definida como a emergência e o desenvolvimento de estruturas essenciais do embrião, manifestando a sua capacidade de originar uma planta normal, sob condições do ambiente favorável. $\mathrm{O}$ vigor, no entanto, compreende um conjunto de características que determinam o potencial fisiológico das sementes, sendo influenciado pelas condições do ambiente e manejo durante as etapas de pré e pós-colheita (Vieira e Carvalho, 1994).

Dentre os testes de vigor considerados mais importantes pela Association of Official Seed Analysts (AOSA, 1983) e pela International Seed Testing Association (ISTA, 2004), pode ser destacado o teste de condutividade elétrica como um dos mais confiáveis, devido a sua objetividade e rapidez, além da facilidade de execução. O teste de condutividade elétrica determina a quantidade de íons presentes na água de embebição e, indiretamente, o vigor das sementes, sendo que o vigor está relacionado à integridade do sistema de membranas celulares (Marcos-Filho et al., 1987). Também, este teste determina o estado de degeneração mais sutil do sistema de membranas celulares das sementes, que é consequência inicial de um processo de deterioração e que não tem condições de ser determinado pelo teste de germinação. Estas transformações degenerativas exercem grande influência no potencial de desempenho das sementes com reflexos na capacidade de armazenamento, na emergência de plântulas no campo, no crescimento e na produtividade das plantas.

Além da condutividade elétrica o vigor das sementes 
pode ser determinado através de testes que poderão predizer as condições em que a cultura irá crescer e se desenvolver. Estas avaliações são realizadas através de parâmetros de crescimento, acúmulo de matéria seca e velocidade de germinação ou emergência.

Sendo assim, este trabalho teve por objetivo avaliar o desempenho de diferentes concentrações de 24epibrassinolídeo na qualidade fisiológica de sementes e no crescimento de plântulas de arroz (Oryza sativa L.) em dois lotes de arroz cv. IRGA 422CL.

\section{MATERIAL E MÉTODOS}

O trabalho foi conduzido no Laboratório de Fisiologia de Sementes e em Casa de Vegetação, do Departamento de Botânica, da Universidade Federal de Pelotas. Foram utilizadas sementes de dois lotes de arroz cv. IRGA $422 \mathrm{CL}$, procedentes do Instituto Riograndense do Arroz. As sementes de ambos os lotes foram submetidas a concentrações crescentes de 24-epibrassinolídeo (zero; 0,01; $0,1 ; 0,4$ e $1,0 \mu \mathrm{M})$ por um período de duas horas e avaliadas por meio dos seguintes testes: teste de germinação (TG) - realizado conforme especificado pelas Regras para Análise de Sementes (Brasil, 1992), sendo utilizadas 200 sementes divididas em quatro subamostras de 50 sementes e três repetições estatísticas, totalizando 600 sementes por tratamento. As sementes foram semeadas em caixas plásticas do tipo gerbox, com papel mata-borrão umedecido com quantidade de água destilada equivalente a duas vezes e meia a massa do substrato e colocadas para germinar em câmara de germinação à temperatura de $25 \pm 1{ }^{\circ} \mathrm{C}$. As avaliações foram realizadas aos 14 dias após a semeadura (DAS), sendo consideradas normais as plântulas que apresentaram um sistema radicular bem formado e coleóptilo perfeito, com uma folha bem desenvolvida (plúmula) no interior ou emergido deste. Os resultados foram expressos em porcentagem de germinação; primeira contagem da germinação (PCG) - efetuada no quinto DAS, sendo consideradas germinadas as sementes cuja protrusão da radícula era maior ou igual a dois milímetros (mm), e os resultados foram expressos em porcentagem de germinação; índice de velocidade de germinação (IVG) - foi determinado conjuntamente ao teste de germinação, conforme descrito por Vieira \& Carvalho (1994), sendo efetuada a contagem do número de plântulas germinadas diariamente, até a estabilização do estande. O IVG foi calculado segundo a fórmula proposta por Maguire (1962), computando o número de sementes germinadas ao dia; comprimento da parte aérea e do sistema radicular
(CPA e CR) - no final do teste de germinação, 14 DAS, vinte plântulas por tratamento, de cada repetição, foram utilizadas para se obter o comprimento da parte aérea e do sistema radicular, os quais foram obtidos por meio de uma régua graduada e os resultados expressos em mm plântula ${ }^{-1}$; massa da matéria fresca da parte aérea e raízes (MFPA e MFR) - obtida gravimetricamente nas mesmas vinte plântulas utilizadas para aferir os comprimentos da parte aérea e das raízes; massa da matéria seca da parte aérea e das raízes (MSPA e MSR) - depois de obtida a massa fresca das plântulas o material vegetal foi levado à estufa e seco a $70 \pm 2{ }^{\circ} \mathrm{C}$ até atingir massa constante, sendo determinada gravimetricamente. $\mathrm{O}$ valor das massas fresca e seca da parte aérea e das raízes foi dividido pelo número de plântulas e os resultados expressos em mg plântula ${ }^{-1}$; condutividade elétrica (CE) - foram utilizadas quatro subamostras de 25 sementes, embebidas durante duas horas em soluções de 24 epibrassinolídeo nas concentrações de zero; 0,$01 ; 0,1 ; 0,4$ e $1,0 \mu \mathrm{M}$, com três repetições estatísticas por tratamento e com suas massas previamente aferidas. Após a embebição nas diferentes soluções de 24-epibrassinolídeo, as amostras foram colocadas em becker contendo $80 \mathrm{ml}$ de água deionizada e mantidas à temperatura de $20{ }^{\circ} \mathrm{C}$. A condutividade elétrica foi medida em condutivímetro Digimed CD-21 após três e 24 horas de embebição e os resultados foram expressos em $\mu \mathrm{S}$ $\mathrm{m}^{-1} \mathrm{~g}^{-1} \mathrm{de}$ semente; teste de emergência de plântulas em casa de vegetação (E) - 200 sementes de arroz, cv. IRGA-422CL, por repetição, foram embebidas por duas horas em soluções de 24-epibrassinolídeo nas concentrações de zero; 0,$01 ; 0,1 ; 0,4$ e 1,0 $\mu \mathrm{M}$. Como substrato foi utilizado areia lavada colocada em bandejas multicelulares de poliestireno expandido e a semeadura realizada manualmente à profundidade de 30 milímetros. A contagem das plântulas emersas foi realizada aos 21 DAS e os resultados expressos em porcentagem de plântulas emergidas; índice de velocidade de emergência de plântulas em casa de vegetação (IVE) - determinado conjuntamente ao teste de emergência de plântulas, conforme descrito por Vieira e Carvalho (1994), sendo efetuada a contagem do número de plântulas emersas diariamente, até a estabilização do estande. O IVE foi calculado segundo a fórmula proposta por Maguire (1962), computando-se o número de plântulas emergidas ao dia.

$\mathrm{O}$ delineamento experimental utilizado foi inteiramente casualizado em esquema fatorial $(2 \times 5)$, sendo dois lotes analisados, cinco concentrações de 24-epibrassinolídeo, com três repetições estatísticas. As médias dos tratamentos foram comparadas pelo teste de Tukey a $5 \%$ de probabilidade e submetidas à análise de regressão polinomial. 


\section{RESULTADOS E DISCUSSÃO}

A germinação das sementes de arroz cv. IRGA 422CL, lotes $\mathrm{A}$ e $\mathrm{B}$, não foi alterada pela aplicação do 24-epibrassinolídeo nas concentrações de 0,01 e 0,1 $\mu \mathrm{M}$. No entanto, houve um decréscimo na porcentagem de germinação, nos dois lotes estudados, quando as sementes foram tratadas com as concentrações mais elevadas do 24-epibrassinolídeo, 0,4 e 1,0 $\mu \mathrm{M}$ (Figura 1). Na primeira contagem da germinação (Figura 2) e no índice de velocidade de germinação (Figura 3), para ambos os lotes, o processo foi mais rápido no controle $(0,0)$ e nas concentrações mais baixas $(0,01$ e $0,1 \mu \mathrm{M}$ de 24 -epibrassinolídeo).

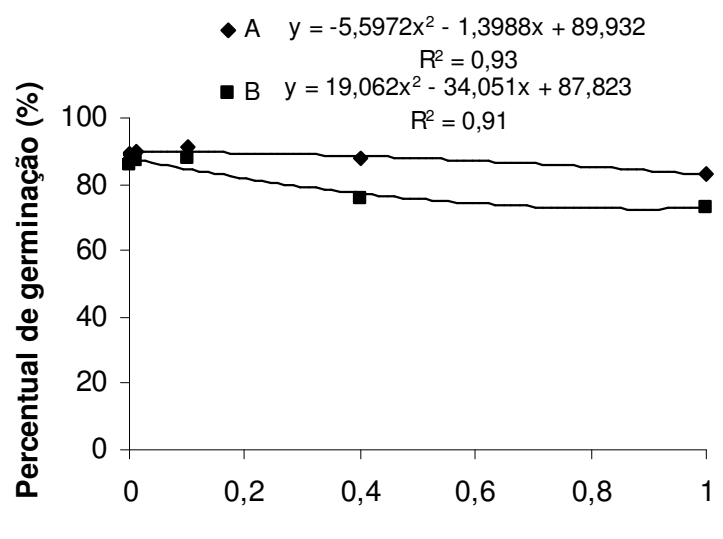

Concentração de 24-epibrassinolídeo (UM )

FIGURA 1. Porcentagem média de germinação de dois lotes de sementes de arroz da cultivar IRGA 422CL em função das diferentes concentrações de 24-epibrassinolídeo $(\mu \mathrm{M})$.

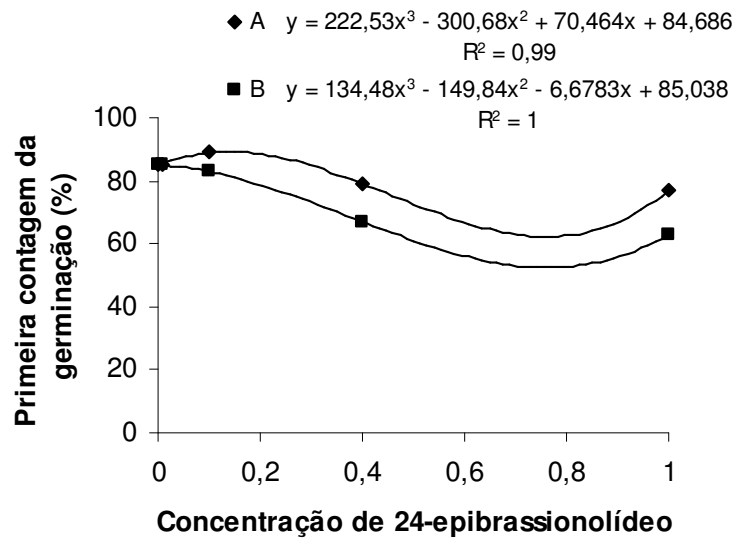

FIGURA 2. Primeira contagem de dois lotes de sementes de arroz da cultivar IRGA 422CL em função das diferentes concentrações de 24epibrassinolídeo $(\mu \mathrm{M})$.

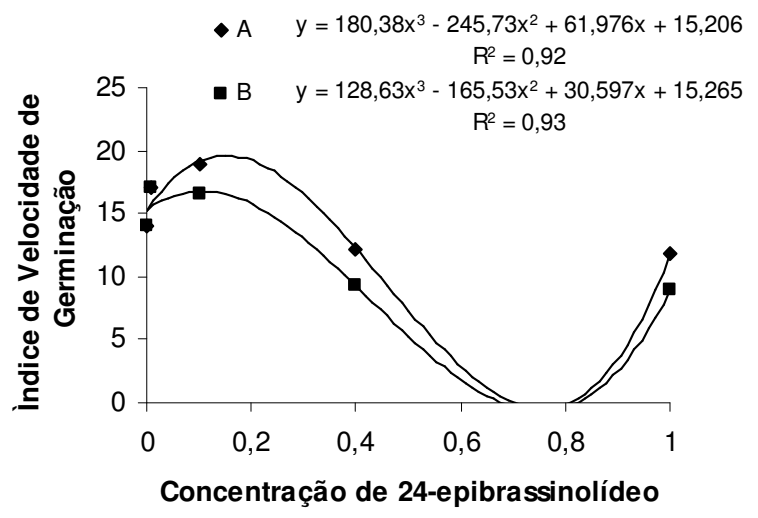

FIGURA 3. Índice de velocidade de germinação de dois lotes de sementes de arroz da cultivar IRGA 422CL em função das diferentes concentrações de 24-epibrassinolídeo $(\mu \mathrm{M})$.

A redução da germinação, observada nas concentrações elevadas, 0,4 e 1,0 $\mu \mathrm{M}$ (Figura 1), coincidiu com o declínio da velocidade do processo (Figura 3 ). Isso evidencia a interferência negativa do 24-epibrassinolídeo em concentrações superiores a $0,1 \mu \mathrm{M}$ para a viabilidade e vigor das sementes de arroz cv. IRGA 422CL, tanto do lote A como do lote B. Dessa forma, podemos inferir que concentrações de até $0,1 \mu \mathrm{M}$ do 24-epibrassinolídeo, são favoráveis aos processos de germinação, primeira contagem da germinação e índice de velocidade de germinação, consequentemente à qualidade fisiológica das sementes de arroz cv. IRGA 422CL.

Ainda não está bem estabelecido de que forma os brassinosteróides atuam na germinação de sementes. Em Lepidium sativum L. a aplicação do 24-epibrassinolide incrementa a germinação, provavelmente por reduzir o efeito inibitório do ácido abscísico (Rao et al., 2002). No entanto, em sementes de café (Coffea arabica L.) a aplicação do regulador de crescimento não teve efeito significativo (Zullo e Adam, 2002). Esses autores afirmam que a indução da germinação, em plântulas de feijoeiro, possa ser o resultado no crescimento do hipocótilo promovido pela aplicação de epibrassinolídeo.

A condutividade elétrica, determinada as três e 24 horas, em ambos os lotes de sementes de arroz cv. IRGA 422CL, evidenciou que as concentrações mais altas $(0,4$ e $1,0 \mu \mathrm{M}$ de 24-epibrassinolídeo) ocasionaram maior lixiviação 
de solutos (Figura 4), provavelmente por induzirem a desorganização do sistema de membranas celulares. A desestruturação e a perda da integridade do sistema de membranas celulares causam alterações no metabolismo e exudação de eletrólitos entre a célula e o meio externo, com reflexos diretos na qualidade fisiológica da semente.

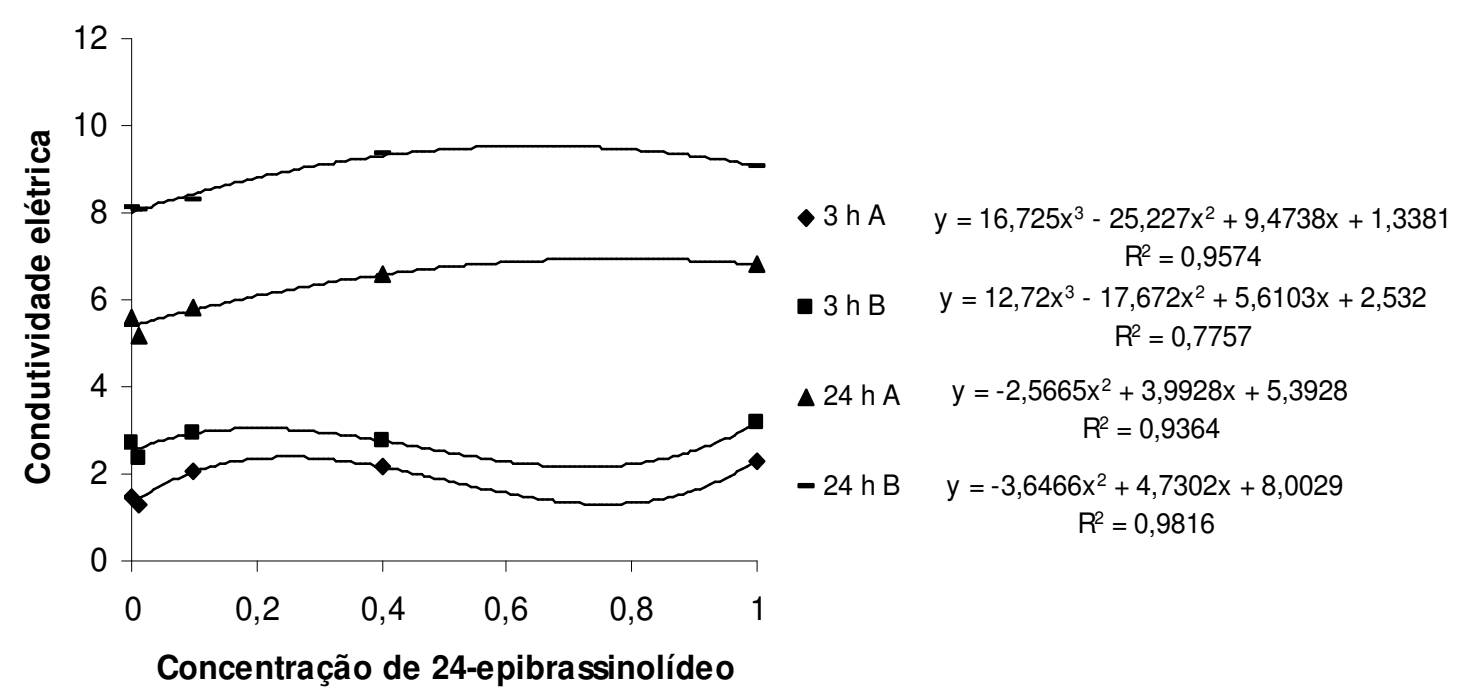

FIGURA 4. Condutividade elétrica $\left(\mu \mathrm{Sm}^{-1} \mathrm{~g}^{-1}\right)$, com três e 24 horas de embebição, de dois lotes de sementes de arroz da cultivar IRGA 422CL em função das diferentes concentrações de 24-epibrassinolídeo ( $\mu M$ M).

Esses resultados permitem deduzir que concentrações superiores a $0,1 \mu \mathrm{M}$ de 24-epibrassinolídeo acentuam o processo de deterioração das sementes de arroz cv. IRGA $422 \mathrm{CL}$ e, consequentemente, pode ser a causa da redução da viabilidade e vigor.

Com base nos resultados dos valores médios do comprimento das raízes (Figura 5) e da parte aérea das plântulas (Figura 6) para os diferentes lotes de sementes de arroz cv. IRGA $422 \mathrm{CL}$, constatou-se que as concentrações de 0,$01 ; 0,1$ e $0,4 \mu \mathrm{M}$ de 24 -epibrassinolídeo, em relação ao controle $(0,0)$, estimularam significativamente $\mathrm{o}$ crescimento das raízes e da parte aérea das plântulas do lote A. No entanto, a concentração de $1,0 \mu \mathrm{M}$ de 24epibrassinolídeo, restringiu o crescimento das raízes e da parte aérea das plântulas. No comprimento das raízes e da parte aérea do lote $\mathrm{B}$ não houve diferenças significativas entre as plântulas controle $(0,0)$ e as tratadas com concentrações de 0,01 e 0,1 $\mathrm{M}$ de 24-epibrassinolídeo. Entretanto, as concentrações de 0,4 e 1,0 $\mu \mathrm{M}$ de 24epibrassinolídeo induziram a redução no crescimento das raízes e da parte aérea das plântulas provenientes do lote B (Figuras 5 e 6 , respectivamente).

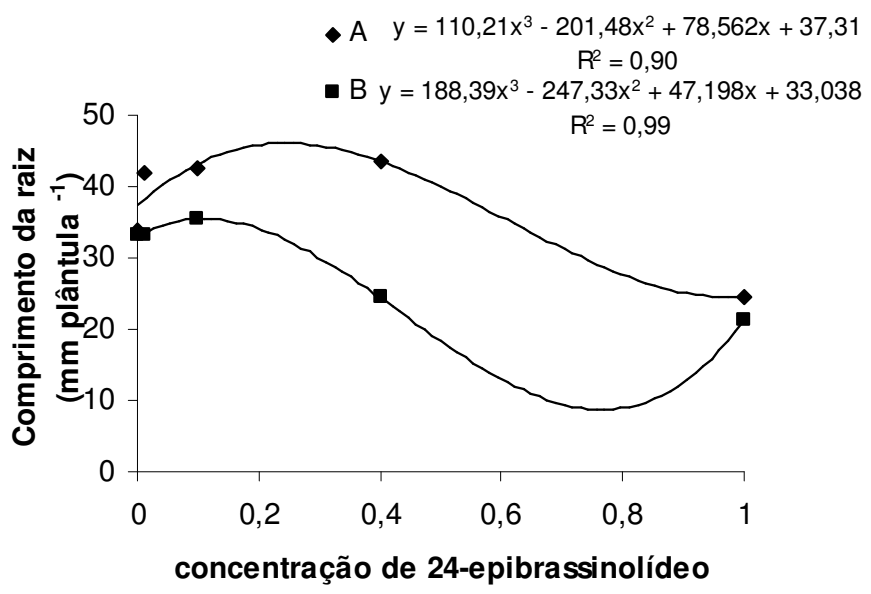

FIGURA 5. Comprimento da raiz de plântulas, provenientes do teste de germinação de sementes de arroz de dois lotes da cv. IRGA 422CL, em função das diferentes concentrações de 24-epibrassinolídeo $(\mu \mathrm{M})$. 


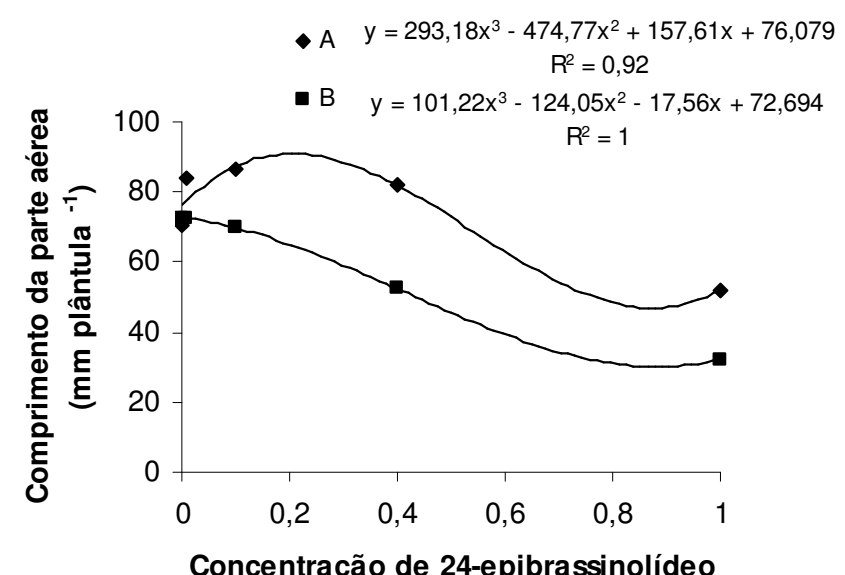

FIGURA 6. Comprimento da parte aérea de plântulas, provenientes do teste de germinação de sementes de arroz de dois lotes da cv. IRGA 422CL, em função das diferentes concentrações de 24-epibrassinolídeo $(\mu \mathrm{M})$.

Recentemente foi detectado em raiz de milho (Kim et al., 2000), tomate (Yokota et al., 2001), Arabdopsis (Bancos et al., 2002) e pêra (Shimada et al., 2003) níveis endógenos de brassinosteróides extremamente baixos. Müssuig etal.,(2003) trabalharam com 24-epibrassinolídeo em concentrações entre 0,05 e $0,1 \mu \mathrm{M}$, e verificaram que estas concentrações estimularam o crescimento da raiz de Arabdopsis. Esses resultados vêm de encontro com os obtidos neste trabalho (lote A), onde as concentrações mais baixas $(0,01$ e $0,1 \mathrm{M})$ foram capazes de estimular e as concentrações superiores de inibir o crescimento da raiz.

A estimulação do crescimento é considerada como um importante papel fisiológico dos brassinosteróides, no entanto, as plântulas de arroz dos dois lotes, da cultivar em estudo, responderam de forma diferente a aplicação do fitohormônio.

A maioria das pesquisas evidencia o papel dos brassinosteróides no comprimento do epicótilo de soja (Yopp et al., 1981), de feijão (Gregory e Mandava, 1982) e pêra (Clouse et al., 1992); no alongamento do hipocótilo de feijão (Yopp et al., 1981), girassol e abóbora e no aumento no comprimento das folhas de beterraba (Katsumi, 1985). A indução do crescimento pelos brassinosteróides parece ser independente de outros fitohormônios (Arteca e Arteca,
2001). No entanto, em Tabebuia alba (Cham) Sandwith o incremento no crescimento da parte aérea é atribuído a associação do 24-epibrassinolídeo com giberelina (Ono et al., 2000) .

A massa fresca do sistema de raízes (Figura 7) e da parte aérea (Figura 8), em ambos os lotes, foram incrementadas significativamente com baixas concentrações e reduzidas nas altas concentrações de 24-epibrassinolídeo, comparadas com o controle $(0,0)$. Já a massa seca das raízes (Figura 9), em ambos os lotes, aumentou significativamente nas concentrações de 0,01 ; 0,1 e $0,4 \mu \mathrm{M}$ e reduziu na concentração maior $(1,0 \mu \mathrm{M})$ de 24-epibrassinolídeo, em comparação as plântulas controle $(0,0)$. No entanto, a massa seca da parte aérea (Figura 10) foi incrementada significativamente nas plântulas tratadas com concentrações mais baixas $(0,01$ e $0,1 \mu \mathrm{M})$ e reduzidas pelas concentrações maiores $(0,4 \mathrm{e}$ $1,0 \mu \mathrm{M})$ de 24-epibrassinolídeo. Em relação às plântulas do controle $(0,0)$ houve um decréscimo significativo da biomassa fresca e seca quando foi utilizada a concentração de 1,0 $\mu \mathrm{M}$. O lote B apresentou resposta similar ao lote A, porém, a indução do acúmulo de massa fresca e seca da raiz foi estimulada apenas pelas concentrações de 0,01 e $0,1 \mu \mathrm{M}$ de 24-epibrassinolídeo, sugerindo uma sensibilidade maior ao regulador de crescimento por este lote.

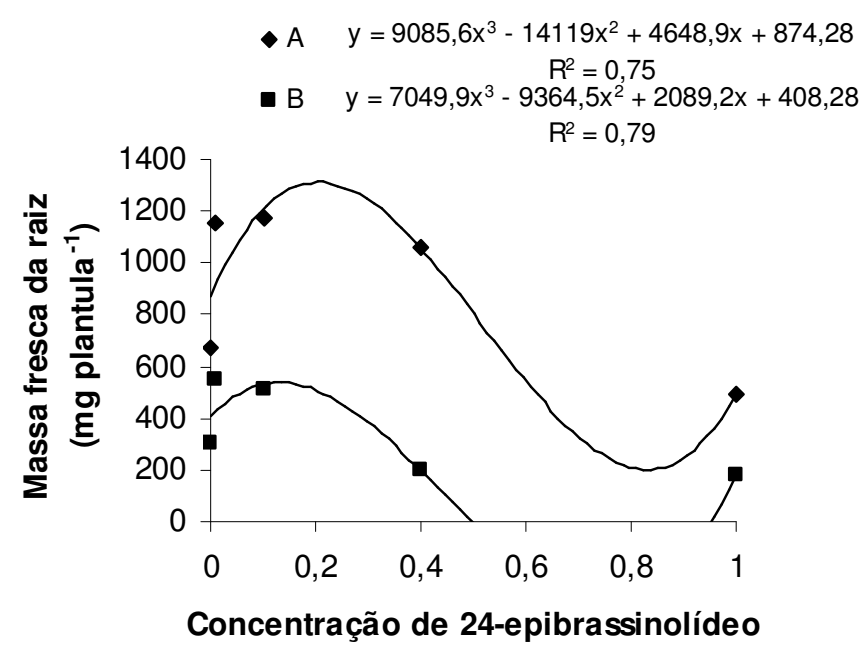

FIGURA 7. Massa fresca da raiz de plântulas, provenientes do teste de germinação de sementes de arroz de dois lotes da cv. IRGA $422 \mathrm{CL}$, em função das diferentes concentrações de 24epibrassinolídeo $(\mu \mathrm{M})$. 


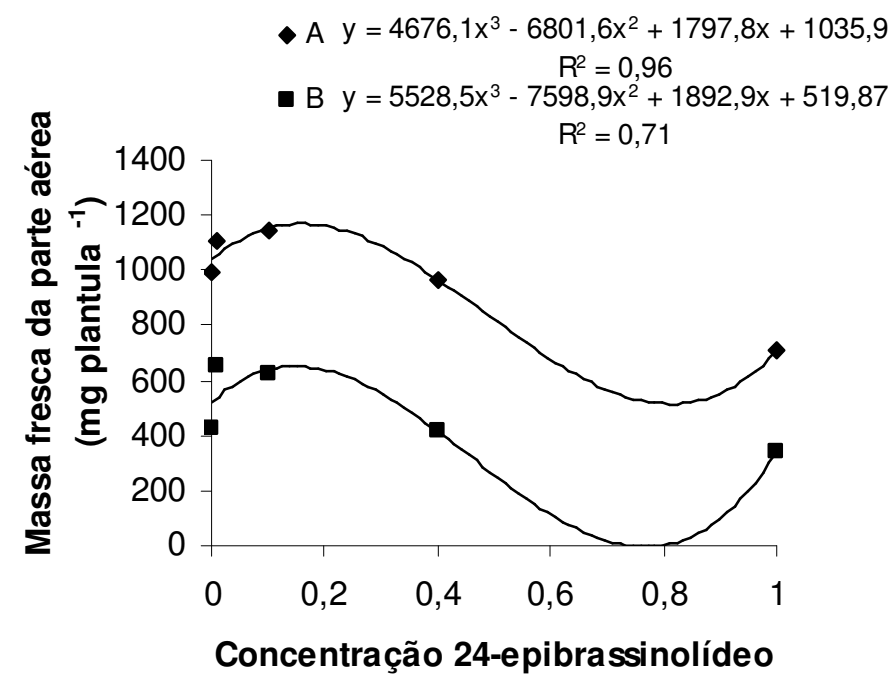

FIGURA 8. Massa fresca da parte aérea de plântulas, provenientes do teste de germinação de sementes de arroz de dois lotes da cv. IRGA 422CL, em função das diferentes concentrações de 24-epibrassinolídeo $(\mu \mathrm{M})$.

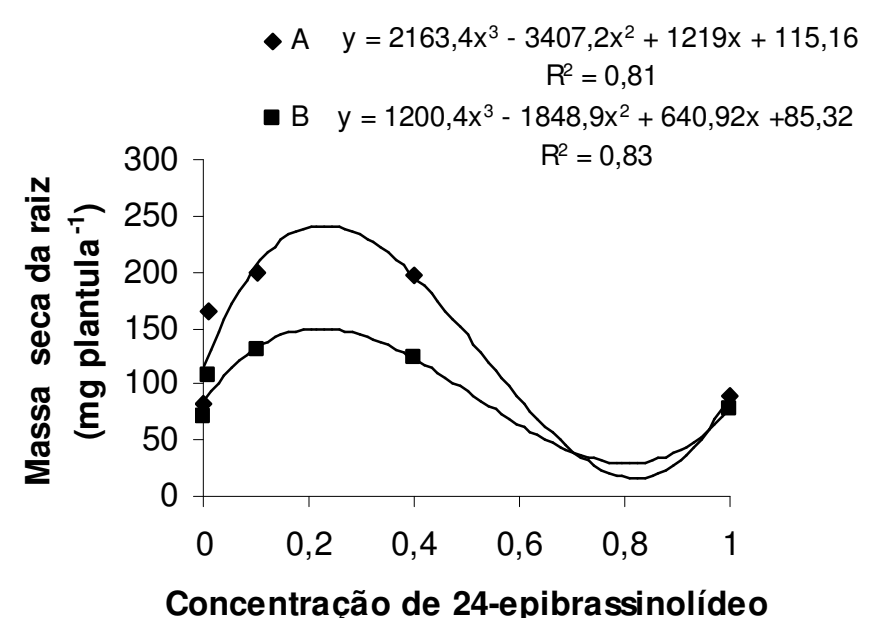

FIGURA 9. Massa seca da raiz de plântulas, provenientes do teste de germinação de sementes de arroz de dois lotes da cv. IRGA 422CL, em função das diferentes concentrações de 24epibrassinolídeo $(\mu \mathrm{M})$.

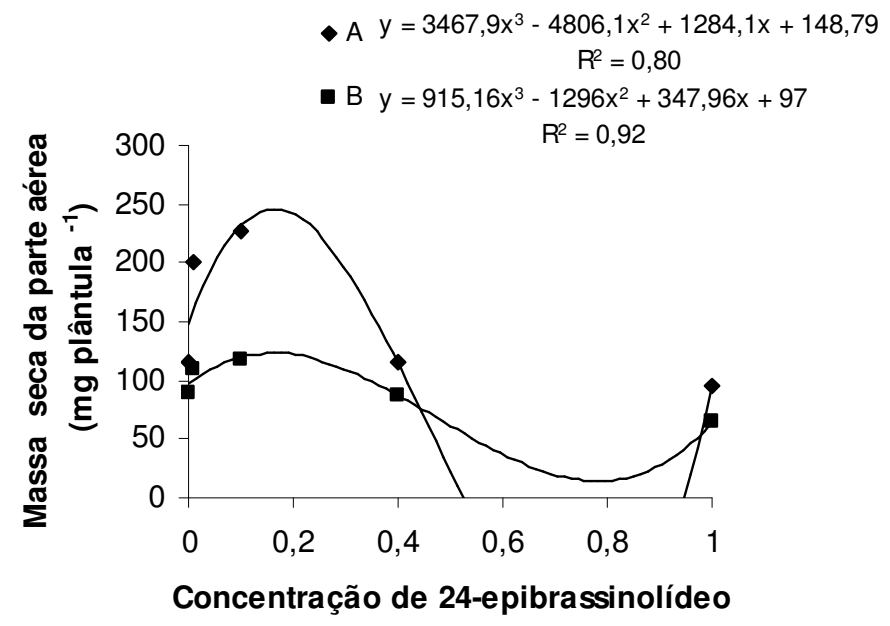

FIGURA 10. Massa seca da parte aérea de plântulas, provenientes do teste de germinação de sementes de arroz de dois lotes da cv. IRGA $422 \mathrm{CL}$, em função das diferentes concentrações de 24-epibrassinolídeo ( $\mu$ M).

Pesquisas têm evidenciado a efetividade do 24epibrassinolídeo em incrementar o acúmulo de biomassa em vários órgãos das plantas. Houve incrementos na massa fresca em grãos de feijoeiro de até 50\% (Meudt et al., 1983), em alface $25 \%$ (Zullo e Adam, 2002), em arroz um acréscimo de massa fresca e seca dos grãos em $32 \%$ e $22 \%$, respectivamente (Lim, 1987), em milho 7\% na massa fresca das espigas e $11 \%$ na massa seca dos grãos (Lim, 1987), em trigo até $37 \%$ na massa seca das sementes (Zullo e Adam,
2002), sendo atribuído à aplicação de 24-epibrassinolídeo, determinado em vários experimentos, tanto em campo como em laboratório.

Os testes de emergência (Figura 11) eíndice de velocidade de emergência de plântulas (Figura 12) em casa de vegetação, dos dois lotes da cultivar de arroz cv. IRGA 422CL em função das diferentes concentrações do 24-epibrassinolídeo, evidenciaram que as concentrações menores, 0,01 e $0,1 \mu \mathrm{M}$ de 24-epibrassinolídeo tiveram efeito positivo na qualidade 
da semente pois proporcionam maiores taxas de crescimento no período inicial do estabelecimento da cultura.

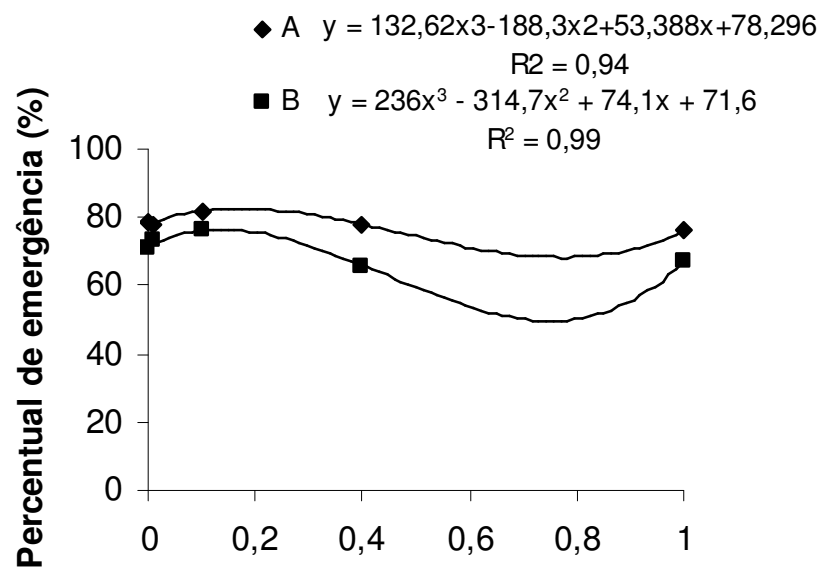

Concentração de 24-epibrassinolídeo

FIGURA11. Emergência de plântulas em casa de vegetação de dois lotes de sementes de arroz da cultivar IRGA 422CL em função das diferentes concentrações de 24-epibrassinolídeo $(\mu \mathrm{M})$.

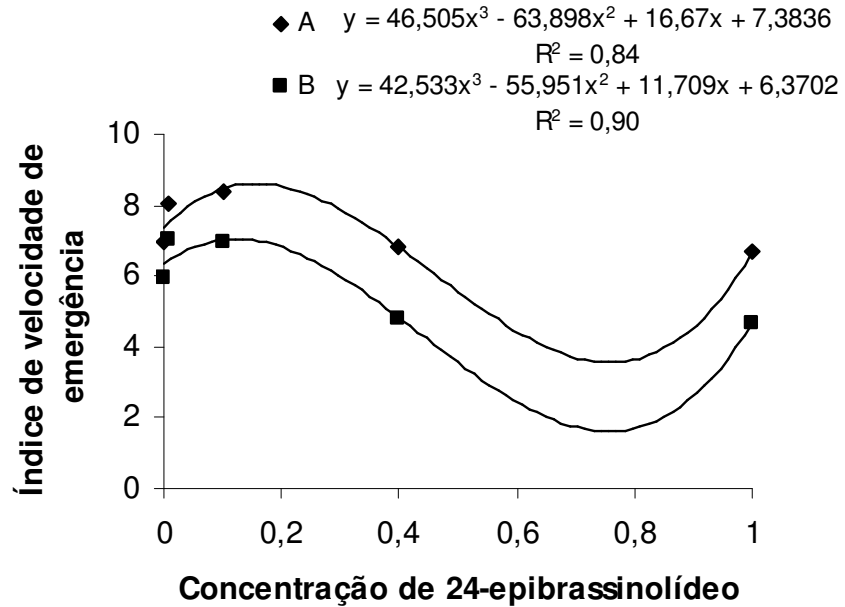

FIGURA 12. Indice de velocidade de emergência de plântulas em casa de vegetação de dois lotes de sementes de arroz da cultivar IRGA 422CL em função das diferentes concentrações de 24-epibrassinolídeo $(\mu \mathrm{M})$.

Em todas as características avaliadas, tanto em laboratório como em casa de vegetação, os resultados foram semelhantes, De modo geral, as concentrações menores
0,4 $\mu \mathrm{M}$ de 24-epibrassinolídeo são ideais para obtenção de resposta positiva na qualidade fisiológica das sementes de arroz cv. IRGA 422CL.

\section{CONCLUSÕES}

Concentrações de até $0,1 \mu \mathrm{M}$ do 24-epibrassinolídeo afetam positivamente o vigor das sementes de arroz cv. IRGA 422CL em relação a sua taxa de crescimento.

Concentrações superiores a 0,1 M de 24-epibrassinolídeo aumentam a condutividade elétrica das sementes de arroz cv. IRGA 422CL e concentrações inferiores a $0,4 \mu \mathrm{M}$ incrementam o crescimento de parte aérea e raiz de plântulas da cv. IRGA 422CL, enquanto concentrações superiores inibem.

\section{REFERÊNCIAS}

ARTECA, J.M.; ARTECA, R.N. Brassinosteroid-induced exaggerated growth in hydroponically grown Arabdopsis plants. Physiologia Plantarum, v.112, n.1, p.104-112, 2001.

ASSOCIATION OF OFFICIAL SEED ANALYSTS. The seed vigor test committee. Seed vigour testing handbook. East Lasing, 1983. 93p. (To the Handbook on Seed Testing. Contribution, 32).

BANCOS, S.; NOMURA T.; SATO T.; MOLNAR G.; BISHOP G.J.; KONKS, C.; YOKOTA T.; NAGY F.; SZEKERES M. Regulation of transcript levels of the Arabdopsis cytochrome p450 genes involved in brassinosteroid biosynthesis. Plant Physiology, v.130, p. 504-513, 2002.

BRASIL. Ministério da Agricultura e Reforma Agrária. Secretaria Nacional de Defesa Agropecuária. Departamento Nacional de Produção Vegetal. Coordenação de Laboratório Vegetal. Regras para Análise de Sementes. 1992. 365 p.

BYRUM, J.R.; COPELAND, L.O. Variability in vigour testing of maize (Zea mays L.) seed. Seed Science and Technology, v.23, n.2, p.543-549, 1995.

CLOUSE, S.D.; ZUREK, D.M.; McMORRIS, T.C.; BAKER, M.E. Effect of brassinolide on gene expression in elongating soy bean epicotyls. Plant Physiology, v.100, n.3, p.1377-1383, 1992.

GREGORY, L.E.; MANDAVA, N.B., The activity and interaction of brassinolide an giberelic acid in mung bean epicotyls, Physiologia Plantarum, v.54, n.3, p. 239-243, 1982. 
INTERNATIONAL SEED TESTING ASSOCIATION ISTA. International Rules for Testing Seeds, 2004. Seed Science and Technology, v. 32, 403p, 2004.

KATSUMI, M. Interaction of a brassinosteroid with IAA and $\mathrm{GA}_{3}$ in the elongation of cucumber hypocotyls sections. Plant Cell and Physiology, v. 26, p. 615-625, 1985.

KIM, S.K.; CHANG, S.C.; LEE, E.J.; CHUNG, W.S.; KIM, Y.S.; HWANG, S.; LEE, J.S. Involvement of brassinosteroids in the gravitropic response of primary root of maize. Plant Physiology, v.123, p. 997-1004, 2000.

LIM, U.K. Effect of brassinolide treatment on shoot growth, photosynthesis, respiration and photorespiration of rice seedlings. Agricultural Research of Seoul National University, v.12, p.9-14, 1987.

MAGUIRE, J.D. Speed of germination aid in selection and evaluation for seedling and vigour. Crop Science, v.2, n.2, p.176-177, Mar./Apr. 1962.

MARCOS FILHO, J.; CÍCERO, S.M.; SILVA, W.R. Avaliação da qualidade fisiológica das sementes. Piracicaba: FEALQ, 1987. 230p.

MEUDT, W.J.; THOMPSON, M.J.; BENNETT, H.W., Investigations on the mechanism of brassinosteroids response. III. Techniques for potential enhancement of crop production, .In. ANNUAL MEETING OF PLANT GROWRH REGULATOR WORKING GROUP, 10., Madison, 1983, Proceedings... p.312-318.

MÜSSUIG, C.; SHIN, G.; ALTMANN, T. Brassinosteroids promote root growth in Arabdopsis. Plant Physiology, v.133, n.3, p.1261-1271, 2003.

ONO, E.O; NAKAMURA, T; MACHADO, S.R; RODRIGUES, J.D. Aplication of brassinosteroids to Tabebuia alba (Bignoniaceae) plants. Revista Brasileira de Fisiologia Vegetal, v.12, n.3, p.187-194, 2000.
POPINIGIS, F. Fisiologia da semente. Brasília, DF: AGIPLAN, 1977. 289p.

RAO, S.S.R.; VARDHINI, B.V.V.; SUJATHA, E.; ANURADHA S. Brassinosteroids-A new class of phytormones. Current Science, v.82, n.10, p.1239-1245, 2002.

SHIMADA, Y.; GODA H.; NAKAMURA, A.; TAKATSUTO, S.; FUJIOKA, S.; YOSHIDA, S. Organspecific expression of brassinosteroid-biosynthetic genes and distribution of endogenous brassinosteroids in Arabidopsis. Plant Physiology, v.131, p. 287-297, 2003.

VIEIRA, R.D.; CARVALHO, N.M. Testes de vigor em sementes. Jaboticabal: FUNEP, 1994. 164p.

YOKOTA T.; SATO, T.; TAKEUCHI, Y.; NOMURA, T.; UNO, K.; WATANABE, T.; TAKATSUTO, S. Roots and shoots of tomato produce 6-deoxo-28-norcathasterone, 6-deoxo-28-nortyphasterol and 6-deoxo-28-norcastasterone, possible precursors of 28-norcastasterone. Phytochemistry, v.58, n.2, p. 233-238, 2001.

YOPP, J.H.; MANDAVA, N.B.; SASSE, J.M. Brassinolide, a growth-promoting stroidal lactone. Activity in selected auxin bioassays. Physiologia Plantarum, v.53, p. 445452, 1981.

ZEPKA, A.P.S.; LARRÉ, C.F.; LOPES, N.F. Avaliação do potencial fisiológico de cultivares de trigo tratadas com o herbicida pendimenthalin. Revista Brasileira de Biociências, v.5, n.2, p.633-635, 2007.

ZULLO, M.T.; ADAM, G. Brassinosteroid phytormonesstructure, bioactivity and applications. Brazilian Journal of Plant Physiology, v.14, n.3, p.143-181, 2002. 